\title{
Peace at the interface of human and machine
}

\author{
James M. Hammel, MD
}

\author{
From Cardiothoracic Surgery, Children's Hospital and Medical Center, Omaha, Neb. \\ Disclosures: Author has nothing to disclose with regard to commercial support. \\ Received for publication June 9, 2017; accepted for publication June 12, 2017; available ahead of print Aug 8, \\ 2017. \\ Address for reprints: James M. Hammel, MD, Cardiothoracic Surgery, Children's Hospital and Medical Center, \\ 8200 Dodge, Omaha, NE 68114 (E-mail: jhammel@ chsomaha.org). \\ J Thorac Cardiovasc Surg 2017;154:1367 \\ $0022-5223 / \$ 36.00$ \\ Copyright (c) 2017 by The American Association for Thoracic Surgery \\ http://dx.doi.org/10.1016/j.jtcvs.2017.06.026
}

The simplest organ "just pumps blood." Yet despite the major contribution that ventricular assist devices have made to the management of children and adults with end-stage heart failure, the long-term imposition of a mechanical blood pump in the human circulation remains a challenging and sometimes dangerous undertaking, due mostly to thrombus formation with resultant thromboembolism or interference with pump function. In this issue of the Journal, Leslie and colleagues ${ }^{1}$ propose some new ideas to favor the establishment of a safe and stable interface between the circulation and the pump.

On the role of "human" in the interaction, this expert panel sheds light on the limitations of present-day coagulation monitoring and management. Certainly, the ability of current, broad assays of coagulation function to predict adverse thrombosis or bleeding is limited. The authors propose that the predictive value of coagulation testing might be improved by modeling relevant shear forces and microvascular anatomy. An even more helpful test would be to improve detection of the earliest manifestations of pathologic thrombosis occurring in vivo, so that anticoagulation might be augmented.

To take best advantage of finer monitoring, however, improved pharmacologic tools for prevention of pathologic thrombosis, with maintenance of salutary hemostasis, are required. The hemostatic system did not evolve to form thrombus on mechanical surfaces. It reacts in different ways to different stimuli. Separately controlling the response of the clotting system to the environment within a blood pump from the response to the ordinary human demands is a second tantalizing focus of the presented work.

On the "machine" side of the relationship, the authors concede that considerable effort has been spent to improve the mechanical factors that contribute to thrombosis. In the adult population, paracorporeal pulsatile devices mostly have been superseded by newer, continuous-flow devices. In children, progress has been slower. The Berlin Heart

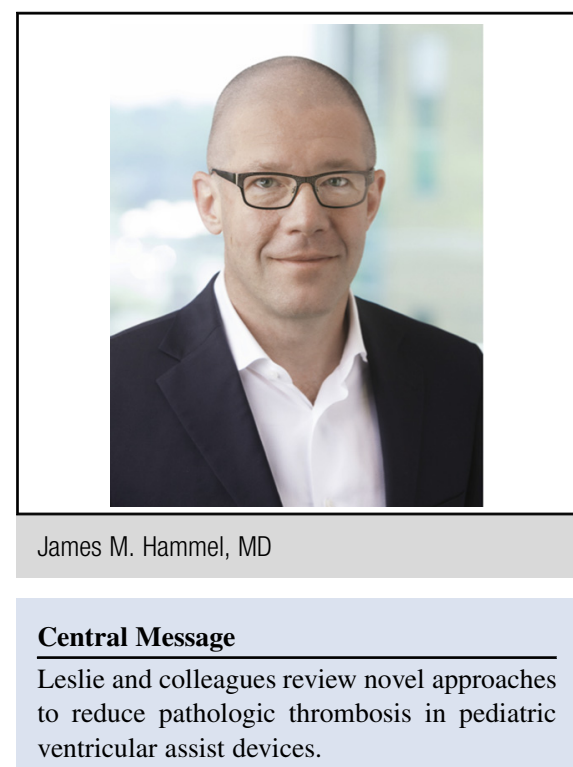

See Article page 1364.

paracorporeal, pulsatile-flow devices, despite a troubling rate of thrombotic and thromboembolic complications especially in the smallest patients, remain in common use. The development of truly small continuous-flow pumps has been hindered by the usual pediatric limitations: small market, wide range of body size, and diverse anatomy. Anyhow, any superiority of current continuous-flow devices in children might turn out to be more subtle. ${ }^{2}$ Without taking sides in this debate, the authors of this opinion offer reference to a fascinating group of papers on the topic of surface modification, which might be beneficial in either type of device.

Which way forward to lessen the morbidity of mechanical circulatory assistance in children? This paper brings to our attention several new avenues of investigation, any or all of which may allow human and machine to coexist more safely.

\section{References}

1. Leslie DC, Waterhouse A, Ingber DE. New anticoagulant coatings and hemostasis assessment tools to avoid complications with pediatric left ventricular assist devices. J Thorac Cardiovasc Surg. 2017;154:1364-6.

2. Nassar MS, Hasan A, Chila T, Schueler S, Pergolizzi C, Reinhardt Z, et al. Comparison of paracorporeal and continuous flow ventricular assist devices in children: preliminary results. Eur J Cardiothorac Surg. 2017;51:709-14. 